\title{
Chemical Formula
}

National Cancer Institute

\section{Source}

National Cancer Institute. Chemical Formula. NCI Thesaurus. Code C48808.

A representation of a substance using symbols for its constituent elements. 